\title{
Sciendo
}

Transport and Telecommunication, 2022, volume 23, no. 1, 1-10

Transport and Telecommunication Institute, Lomonosova 1, Riga, LV-1019, Latvia

DOI 10.2478/ttj-2022-0001

\section{MODELING OF MOBILE AND FIXED BROADBAND SUBSCRIPTIONS OF COUNTRIES WITH FRACTIONAL CALCULUS}

\author{
Nisa Özge Önal Tuğrul ${ }^{1, *}$, Cennet Başer ${ }^{1}$, Esra Ergün ${ }^{1}$, Kamil Karaçuha ${ }^{1}$, Vasil \\ Tabatadze $^{1}$, Sebahattin Eker ${ }^{1}$, Ertuğrul Karaçuha ${ }^{1}$, Kevser Şimşek ${ }^{1}$ \\ ${ }^{1}$ Istanbul Technical University, Informatics Institute, \\ Information and Communication Engineering, Istanbul, Turkey \\ \{onal16, baser18, karacuha17,ergunesr,tabatadze, ekerseb, karacuhae, simsek18\}@itu.edu.tr \\ *Correspondence: onal16@itu.edu.tr
}

\begin{abstract}
Today, operators have become the resource of telecommunications data. Therefore, knowledge about subscriptions is easily available for most countries. In recent years, high-speed mobile internet access subscriptions are also increasing rapidly. There are two important subscriptions reviewed by The International Telecommunication Union (ITU): mobile broadband (MBB) subscriptions and Fixed broadband (FBB) subscriptions. In this study, we proposed an original mathematical model employing the fractional analysis theory and evaluate its validity by modeling the mobile broadband and fixed broadband subscriptions of six countries including France, Italy, Turkey, Germany, Spain, and the U.K. Later, we compared the Fractional Model we developed with the Polynomial Model. The results show that the Fractional Model is superior to the conventional Polynomial Model in modeling broadband subscriptions. For all selected countries, our proposed Fractional approach outperforms conventional polynomial regression. For all investigation categories, on average, the fractional approach works better by at least $10 \%$ and at most $30 \%$.
\end{abstract}

Keywords: Fractional calculus; mobile and fixed broadband; broadband subscriptions; MAPE; mathematical modeling

\section{Introduction}

Social and economic indicators, financial trends, and the economic structure of a country are very important for domestic and foreign investors. Accurate and logical studies are required to make reasonable infrastructure investments. Government studies are not sufficient by themselves to catch the trends or obtain clues for the future in the market. Therefore, for data interpretation, that first, data must be modeled and mathematically expressed as a function. Then, to extract or deduce information from the data, some properties of that function can be utilized. Public and private companies' collaborations are critical for lowering the communication costs and there is huge competition in the marketplace of telecommunications. This competition has some implications, such as cost reduction, increased quality, and facilitating access to worldwide services. As a result, access to telecommunication services increased greatly over the past two decades. The International Telecommunications Union (ITU) states that there were more than 5 billion mobile subscriptions worldwide in the late $2009 \mathrm{~s}$ and there is no other technology that spreads so fast in the world (Ahn and Lee, 1999).

There are different kinds of data sources in the telecommunications sector. Also, there are some essential data types related to subscription information that is available for a large number of countries. These data types are subscriptions, access, and usage (Albon, 2006). Due to the differences in regulations, there are some differences among the data reported by countries. Some countries do not use the definition regulated by ITU (Ahn and Lee, 1999; Albon, 2006; Briglauer, 2011; Srinuan, 2010; Unwired Insight, 2007). Recently, the usage and the coverage of high-speed mobile Internet access have been increasing in the world. The increase in the access rates to the high-speed mobile internet for each country strengthens worldwide internet access more. Thus, the social value and the importance of the network increases which leads to an increase in subscriptions in return.

There are two important subscriptions reviewed by ITU: Mobile broadband (MBB) subscriptions and Fixed broadband (FBB) subscriptions. MBB subscriptions are mobile service subscriptions that provide connection to the Public Switched Telephone Network (PSTN) regarding the cellular systems. Mobile subscriptions include the following: analog and digital cellular systems (IMT-2000 (Third 
Generation, 3G), 4G subscriptions, and all mobile cellular subscriptions, excluding mobile broadband subscriptions regarding both USB modems and data cards. Besides, general mobile data services subscriptions, custom trunked mobile radio, radio call or telepoint, and also telemetry services are not included in Mobile subscriptions (Pita Barros et al., 2000; Narayana, 2010; Ward and Woroch, 2004; Sugolov, 2005; Rodini et al., 2003; Horvath and Maldoom, 2002). FBB subscriptions term fixed subscriptions to the public Internet. FBB can provide subscriptions at very high speeds such as $256 \mathrm{kbit} /$ s, sometimes even much higher. Fixed broadband Internet contains a set of technological systems. These are cable modem, fiber, DSL, and also other fixed broadband technology. For the last one, satellite broadband Internet, Ethernet LANs, fixed-wireless access, Wireless Local Area Network, WiMAX are examples. Subscribers with access to data communication over mobile cellular networks such as the Internet are separated (Pita Barros et al., 2000; Narayana, 2010; Ward and Woroch, 2004; Sugolov, 2005; Rodini et al., 2003; Horvath and Maldoom, 2002).

Since 2000, there has been a rapid increase in mobile phone subscriptions. This situation also led to an increase in the penetration rate and use of telecom services. Further, mobile phones have created a competitive situation for existent subscribers and future subscriptions. But it is not known how this will affect the status of landline subscriptions. It depends on the relationship between mobile and landline phones. Literature studies focus on the relationship between fixed and mobile phones in four ways; developed economies, transition, emerging and low economies (Garbacz and Thompson, 2005; 2007).

In this study, the modeling of mobile and fixed broadband subscriptions of 6 countries including Turkey, Germany, the U.K., France, Italy, and Spain with a newly proposed approach will be implemented. The reason behind the need for modeling of the given datasets as mentioned before, modeling the discrete data as a continuous curve with minimum error enables researchers, investigators, institutes, and government to extract more information about the dataset and to catch the clues or missing data compared to using simply discrete datasets. First, we will offer an original mathematical utilizing Fractional Calculus Theory. The name of the present approach is Fractional Model-3. Later, we will compare the performance of this new model to our previously proposed Fractional Model-1, Fractional Model-2, and conventional Polynomial method. The selected countries are more or less have comparable populations and similar regulations. The subscriptions of the countries will be modeled with the help of the Fractional Models 1, 2, 3, and Polynomial Model. The comparison of these four mathematical models will be discussed.

The framework of this study is as follows. Section 2 provides the formulation of the problem and the method, section 3 illustrates the experimental results, and lastly, section 4 provides the conclusion.

\section{Formulation of the Problem}

In this section, there exist three sub-section. The first section is devoted to the main approach proposed in the present study. Apart from the first sub-section, the other sub-sections are included for two reasons. First is for the sake of completeness and secondly, the readers can understand and follow the mainframe of the study easily without any other references.

The new approach is introduced for modeling which is called Fractional Model-3 in the following sub-section. The model utilizes the fractional calculus and the least-squares method. The mathematical manipulations, satisfying the differential equation, and obtaining the unknown coefficient coming from Taylor Expansion are expressed. Then, key points and differences of the previous modeling approaches (Fractional Model-1 and Model-2) are briefly highlighted in the following two sub-sections since all methods are compared in Section 3.

\subsection{The mathematical formulation of new developed Fractional Model-3}

In this study, four different mathematical models are used for modeling of country's subscriber numbers of $\mathrm{MBB}$ and FBB. These models are the Polynomial Model and our developed Fractional Models. As the first one, a new fractional approach model whose name is Fractional Model-3 is presented mathematically. We aim to create a new mathematical approach with the fractional derivative approach.

Firstly, during the study, the definition of Caputo's fractional derivative is taken into account and fractional derivative $\mathfrak{D}_{x}^{\alpha}$ will be determined as Eq.(1) (Önal et al., 2019);

$\mathfrak{D}_{x}^{\alpha} f(x)=\frac{d^{\alpha} f(x)}{d x^{\alpha}}=\frac{1}{\Gamma(1-\alpha)} \int_{0}^{x} \frac{f^{(1)}(t) d t}{(x-t)^{\alpha}}$,

where $\alpha$ is fractional derivative and varies from 0 to $1, f^{(1)}$ is denoted as the first derivative of the function and finally, $\Gamma(\alpha)$ is the Gamma Function and can be defined as $\Gamma(1-\alpha)=\int_{0}^{\infty} t^{-\alpha} e^{-t} d t$. 
The new model which uses the theory of fractional calculus improves modeling regarding the convergence and error minimization according to the Polynomial Model results (Önal et al., 2019; Podlubny, 1998). The assumed fractional derivative of $f(x)$ is shown in Eq. (2). Note that, the right-hand side of the expression is inspired by the Taylor expansion and the first derivative operation (Önal et al., 2019; Podlubny, 1998). This approach is called Fractional Model-3.

$\mathfrak{D}_{x}^{\alpha} f(x)=\frac{d^{\alpha} f(x)}{d x^{\alpha}}=\sum_{n=1}^{\infty} a_{n}(n \alpha) x^{n \alpha-1}$,

where derivative order $\alpha$ and $\alpha \in(0,1)$.

Here, $f(x)$ corresponds to the fixed and mobile broadband subscriptions value regarding the time which is shown as $x$ in Eq. (2). The aim is to obtain optimized coefficient values of $f(0)$ and $a_{n}$ for the best modeling performance. To solve the fractional differential given in Eq. (2), the Laplace transform is taken since the differential equation is reduced to an algebraic equation.

The Laplace transform of Eq. (2) is given as below (Podlubny, 1998):

$\mathcal{L}\{f(x)\}=F(s)=\frac{f(0)}{s}+\sum_{n=1}^{\infty} \frac{a_{n}(n \alpha)}{s^{\alpha n}} \Gamma(n \alpha)$.

Here, $\mathcal{L}$ is denoted by the Laplace transform whereas, $\mathcal{L}^{-1}$ is given as the inverse Laplace transform operation. After reducing the differential equation into an algebraic equation as given above, the inversion procedure is followed to find $f(x)$ as:

$\mathcal{L}^{-1}\{F(s)\}=f(x)=f(0)+\sum_{n=1}^{\infty} \frac{a_{n} \Gamma(n \alpha+1) x^{\alpha(n+1)-1}}{\Gamma(\alpha(n+1))}$.

The summation in Eq. (4) needs to be truncated to $N$ to obtain numerical results. The truncated form of Eq. (4) is given in Eq. (5).

$f(x) \cong f(0)+\sum_{n=1}^{N} \frac{a_{n} \Gamma(n \alpha+1) x^{\alpha(n+1)-1}}{\Gamma(\alpha(n+1))}$.

After obtaining the mathematical formulation for the unknown $f(x)$ function, it is time to introduce the dataset to the problem because there exist unknowns in Eq. $(5)\left(f(0), a_{n}\right)$. Therefore, these unknown constant coefficients should be determined. To achieve this, the present study employs the leastsquares method for fixed and mobile broadband subscriptions value (Royston and Altman, 1994; Önal et al., 2019). The discrete data can be denoted as below.

$P_{i}=\left[\begin{array}{llll}p_{0} & p_{1} & \ldots & p_{K}\end{array}\right]$

$x_{i}=\left[\begin{array}{llll}x_{0} & x_{1} & \ldots & x_{K}\end{array}\right]$,

where $i=0,1,2, \ldots, K$.

The dataset has a dimension $K+1$. Here, $x_{i}$ stands for the time, $P_{i}$ represents fixed and mobile broadband subscriptions value in that specific time. In Eq. (8), the square of the error between the value $P_{i}$ and $f\left(x_{i}\right)$ is defined as $\epsilon_{i}$. The aim is to reduce the total error resulting from each data point as much as possible.

$\left(\epsilon_{i}\right)^{2}=\left(p_{i}-f\left(x_{i}\right)\right)^{2}$.

In Eq. (9), the square of the total error is provided. To minimize Eq. (9), the least-squares method is employed as mentioned before. To achieve this, the derivative of the square of total error concerning each unknown should be equated to zero as given in Eq. (10) (Önal et al., 2019).

$$
\begin{aligned}
& \epsilon_{T}^{2}=\sum_{i=0}^{K}\left[p_{i}-\left\{f(0)+\sum_{n=1}^{N} \frac{a_{n} \Gamma(n+1) x_{i}^{\alpha+n-1}}{\Gamma(\alpha+n)}\right\}\right]^{2} . \\
& \frac{\partial \epsilon_{T}^{2}}{\partial f(0)}=0, \frac{\partial \epsilon_{T}^{2}}{\partial a_{1}}=0, \frac{\partial \epsilon_{T}^{2}}{\partial a_{2}}=0, \ldots \frac{\partial \epsilon_{T}^{2}}{\partial a_{N}}=0 .
\end{aligned}
$$


Eq. (10) leads to having $N+1$ equation for $N+1$ unknowns. Therefore, this system can be solvable. After taking derivatives given in Eq. (10), a system of linear algebraic equations (SLAE) is obtained as in Eq. (11) - Eq. (14):

$[A]_{N+1 \times N+1}[\Omega]_{N+1 \times 1}=[B]_{N+1 \times 1}$,

$[\Omega]=\left[\begin{array}{lllllll}f(0) & a_{1} & a_{2} & \ldots & a_{n} & \ldots & a_{N}\end{array}\right]^{T}$,

$[\mathrm{B}]=\left[\sum_{i=0}^{K} P_{i} \sum_{i=0}^{K} P_{i} x_{i}^{\alpha} \sum_{i=0}^{K} P_{i} x_{i}^{\alpha+1} \quad \ldots \sum_{i=0}^{K} P_{i} x_{i}^{\alpha+N-1}\right]^{T}$,

$A=\left[\begin{array}{ccccc}k+1 & \sum_{i=1}^{k} c_{1}\left(x_{i}\right) & \sum_{i=1}^{k} c_{2}\left(x_{i}\right) & \cdots & \sum_{i=1}^{k} c_{N}\left(x_{i}\right) \\ \sum c_{1}\left(x_{i}\right) & \sum c_{1}\left(x_{i}\right) c_{1}\left(x_{i}\right) & \sum c_{1}\left(x_{i}\right) c_{2}\left(x_{i}\right) & \cdots & \sum c_{1}\left(x_{i}\right) c_{N}\left(x_{i}\right) \\ \sum c_{2}\left(x_{i}\right) & \sum c_{2}\left(x_{i}\right) c_{1}\left(x_{i}\right) & \sum c_{2}\left(x_{i}\right) c_{2}\left(x_{i}\right) & \cdots & \sum c_{2}\left(x_{i}\right) c_{N}\left(x_{i}\right) \\ \vdots & \vdots & \vdots & \vdots \\ \vdots c_{N}\left(x_{i}\right) & \sum c_{N}\left(x_{i}\right) c_{1}\left(x_{i}\right) & \sum c_{N}\left(x_{i}\right) c_{2}\left(x_{i}\right) & \cdots & \sum c_{N}\left(x_{i}\right) c_{N}\left(x_{i}\right)\end{array}\right]$,

where,

$c_{n}(x, \alpha)=\frac{\Gamma(n \alpha+1)}{\Gamma(\alpha(n+1))} x^{\alpha(n+1)-1}, \quad n=1,2, \ldots, N$.

Here, $T$ corresponds to the transpose operation in Algebra. Then, by matrix inversion, the vector containing unknowns $[\Omega]_{N+1 \times 1}$ can be obtained as Eq. (16):

$[\Omega]_{N+1 \times 1}=[\mathrm{A}]_{N+1 \times N+1}^{-1}[B]_{N+1 \times 1}$

where, $[\mathrm{A}]^{-1}$ stands for the inverse of the matrix $[\mathrm{A}]$.

\subsection{Review on Fractional Model-1}

Fractional Model-1 was firstly proposed in (Önal et al., 2019). In that study, the function $f(x)$ which is the function aimed to model is assumed to satisfy the following expression which was deduced from Taylor Expansion and the first derivative of $f(x)$ as given Eq. (17).

$$
\frac{d^{\alpha} f(x)}{d x^{\alpha}}=\sum_{n=1}^{\infty} a_{n} n(x)^{n-1}, \quad 0<\alpha<1 \text {. }
$$

Again, to solve the equation above, the Laplace Transform is taken as given in Eq. (18) and then, the differential equation is reduced to an algebraic equation.

$F(s)=\frac{f(0)}{s}+\sum_{n=1}^{\infty} a_{n} n \frac{\Gamma(n)}{s^{n+\alpha}}$.

After Inverse Laplace Transform, the required function $f(x)$ is found as Eq. (19):

$f(x) \cong f(0)+\sum_{n=1}^{N} a_{n} n \frac{\Gamma(n+1) x^{\alpha+n-1}}{\Gamma(n+\alpha)}$

Here, $f(0)$ and $a_{n}$ constant coefficients are not known. To find these coefficients, the leastsquares method is employed. Then, the operations of the Eq. (6) - Eq. (14) are applied here to determine unknowns with minimum error.

\subsection{Review on Fractional Model-2}

Fractional Model-2 was the improved version of Fractional Model-1. Again, the assumed fractional derivative of $f(x)$ is shown in Eq. (2). The expression is deduced from Taylor Expansion and the first derivative of $x^{n+\alpha}$ (Modified version of the Taylor Expansion). 
$\frac{d^{\alpha} f(x)}{d x^{\alpha}}=\sum_{n=0}^{\infty} a_{n}(n+\alpha) x^{n+\alpha-1}$.

Then, the Laplace Transform of the $f(x)$ function is found as Eq. (21):

$F(s)=\frac{f(0)}{s}+\sum_{n=0}^{\infty} a_{n} \frac{\Gamma(n+\alpha+1)}{s^{n+2 \alpha}}$.

After inversion of Laplace Transform, the required function $f(x)$ is approximated as follows Eq. (22). Then, the operations of the Eq. (6) - Eq. (14) are applied here as well.

$f(x) \cong f(0)+\sum_{n=0}^{N-1} a_{n} \frac{\Gamma(n+\alpha+1)}{\Gamma(n+2 \alpha)} x^{n+2 \alpha-1}$.

\subsection{Comparision of the Fractional Models}

As a result, we have three different Fractional Models. As given in the previous section, the proposed functions, $f(x)$ stand for modeling the data with minimum error and given in Table 1 regarding different fractional models. In this manner, mathematically, differences between the models will be seen more clearly in the corresponding table.

Table 1. $\boldsymbol{f}(\boldsymbol{x})$ functions of Fractional Models

\begin{tabular}{|l|l|}
\hline Fractional Models & $\boldsymbol{f}(\boldsymbol{x})$ Functions \\
\hline Fractional Model-1 & $f(x) \cong f(0)+\sum_{n=1}^{N} a_{n} n \frac{\Gamma(n+1) x^{\alpha+n-1}}{\Gamma(n+\alpha)}$ \\
\hline Fractional Model-2 & $f(x) \cong f(0)+\sum_{n=0}^{N-1} a_{n} \frac{\Gamma(n+\alpha+1)}{\Gamma(n+2 \alpha)} x^{n+2 \alpha-1}$ \\
\hline Fractional Model-3 & $f(x) \cong f(0)+\sum_{n=1}^{N} a_{n} \frac{\Gamma(n \alpha+1) x^{\alpha(n+1)-1}}{\Gamma(\alpha(n+1))}$ \\
\hline
\end{tabular}

\section{Application and Results}

In this paper, we examine mobile and fixed broadband subscriptions of France, Italy, Turkey, Germany, Spain, and the U.K from 2010 to the 2019 year with Q2 (Quartile-2) and Q4 (Quartile-4) datasets. Data obtained from OECD broadband portal (OECD, 2021). The dataset includes six countries for mobile and fixed broadband subscriptions. See the Figure 1.

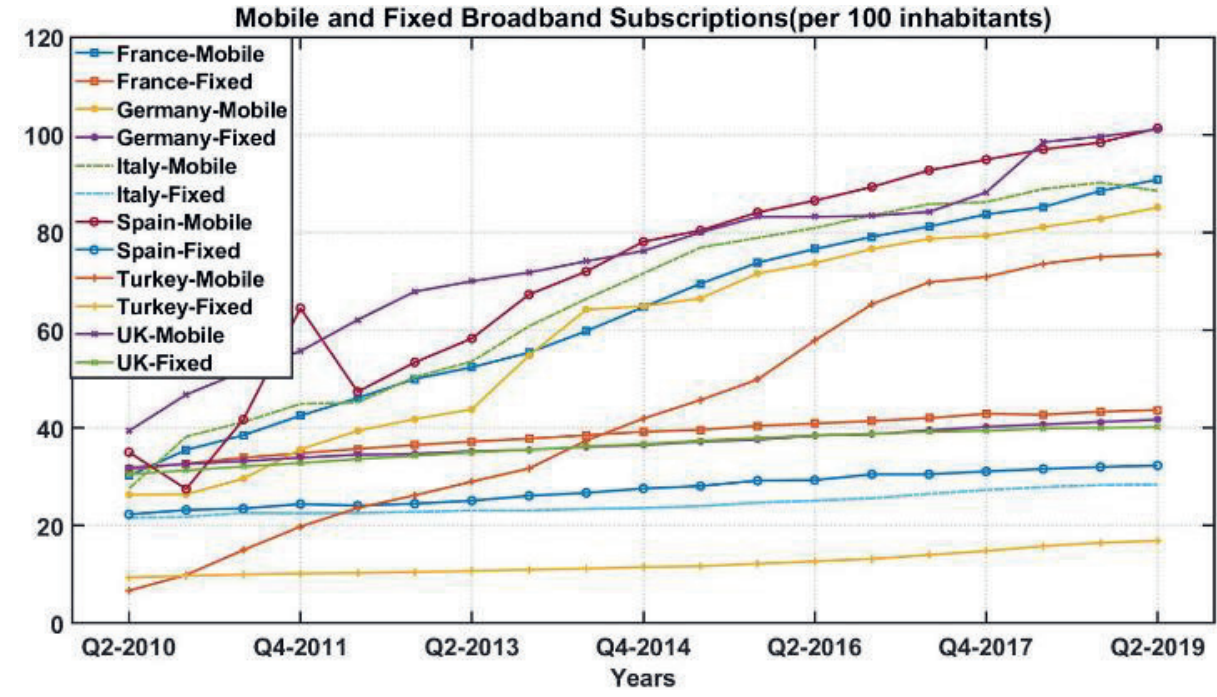

Figure 1. Mobile and fixed broadband subscriptions per 100 habitants for countries 
This section reports results using our newly proposed Fractional Model-3, Fractional Model-1, Fractional Model-2, and Polynomial for two different exponent $N$ values $(N=5$ and $N=10)$. As it was highlighted in our previous studies, when $N$ in the equation is increased, the error in both modeling approaches is reduced. Therefore, we observed the results by increasing the $N$ value. The cases of $N=5$ and $N=10$ for modeling of fixed and mobile broadband subscriptions are investigated and the results are provided in Table 2.

In this study, we compared the results of these four models. For this, Mean Absolute Percentage Error (MAPE) is employed (Gautschi, 1997). Eq. (22) shows the MAPE formulation.

$M A P E=\frac{1}{K} \sum_{i=0}^{K}\left|\frac{P(i)-f(i)}{P(i)}\right| x 100$,

where $P(i)$ and $f(i)$ are real and predicted values, respectively.

MAPE results of the mobile and fixed broadband subscriptions of France, Italy, Turkey, Germany, Spain, and the U.K. according to techniques of Polynomial and Fractional Models are given in Table 2.

When $N$ is 5 , modeling of mobile broadband subscription yields $2.730 \%, 2.739 \%, 1.0728 \%$, and $1.5254 \%$ average MAPE for Fractional Model-1, Fractional Model-2, Fractional Model-3, and Polynomial Method, respectively. Modeling fixed broadband subscriptions yields $0.3888 \%, 0.3889 \%$, 0.36555\%, and $0.4084 \%$ for Fractional Model-1, Fractional Model-2, Fractional Model-3 and Polynomial Method, respectively. For both MB and FB cases, Fractional Model-3 outperforms other models. For the mobile broadband subscriptions, the lowest MAPE values are obtained for France while the largest errors are obtained for Spain. For the fixed-broadband subscriptions, the lowest MAPE values are also obtained for France with similar error values with $<0.01 \%$ error difference between any two models. Fractional Model-1 and Fractional Model-2 produced similar error rates for both mobile broadband and fixed broadband. All fractional models produced smaller error values compared to the Polynomial Method. Note that, when the optimized fractional order is equal to 1, the MAPE results of the Fractional approach and Polynomial approach are the same.

Table 2. Modeling results of fixed and mobile broadband subscriptions (per 100 inhabitants)

\begin{tabular}{|c|c|c|c|c|c|c|c|c|c|}
\hline & & MODELS & Results & France & Germany & Italy & Spain & Turkey & U.K. \\
\hline \multirow{14}{*}{ il } & \multirow{7}{*}{ 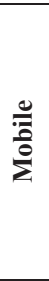 } & \multirow{2}{*}{$\begin{array}{l}\text { Fractional } \\
\text { Model-1 }\end{array}$} & MAPE & 1.113 & 2.238 & 2.553 & 5.327 & 3.4714 & 1.734 \\
\hline & & & $\alpha$ value & 0.001 & 1 & 0.001 & 0.001 & 1 & 0.442 \\
\hline & & \multirow{2}{*}{$\begin{array}{l}\text { Fractional } \\
\text { Model-2 }\end{array}$} & MAPE & 1.1132 & 2.2382 & 2.5539 & 5.3276 & 3.4714 & 1.7337 \\
\hline & & & $\alpha$ value & 0.501 & 1 & 0.501 & 0.501 & 1 & 0.721 \\
\hline & & \multirow{2}{*}{$\begin{array}{l}\text { Fractional } \\
\text { Model-3 }\end{array}$} & MAPE & 1.036 & 2.2382 & 1.4993 & 4.6670 & 3.4714 & 1.7342 \\
\hline & & & $\alpha$ value & 0.602 & 1 & 0.455 & 0.007 & 1 & 0.869 \\
\hline & & Polynomial & MAPE & 1.4061 & 2.2382 & 3.1356 & 5.6163 & 3.4714 & 1.7606 \\
\hline & \multirow{7}{*}{ : } & \multirow{2}{*}{$\begin{array}{l}\text { Fractional } \\
\text { Model-1 }\end{array}$} & MAPE & 0.186 & 0.195 & 0.4496 & 0.6837 & 0.696 & 0.123 \\
\hline & & & $\alpha$ value & 1 & 1 & 1 & 0.01 & 1 & 0.976 \\
\hline & & \multirow{2}{*}{$\begin{array}{l}\text { Fractional } \\
\text { Model-2 }\end{array}$} & MAPE & 0.1864 & 0.1951 & 0.4496 & 0.6839 & 0.696 & 0.1227 \\
\hline & & & $\alpha$ value & 1 & 1 & 1 & 0.501 & 1 & 0.988 \\
\hline & & \multirow{2}{*}{$\begin{array}{l}\text { Fractional } \\
\text { Model-3 }\end{array}$} & MAPE & 0.1834 & 0.1951 & 0.4496 & 0.6018 & 0.6408 & 0.1226 \\
\hline & & & $\alpha$ value & 0.032 & 1 & 1 & 0.449 & 0.446 & 0.989 \\
\hline & & Polynomial & MAPE & 0.1864 & 0.1951 & 0.4496 & 0.8005 & 0.6961 & 0.123 \\
\hline \multirow{14}{*}{$\frac{\theta}{\pi}$} & \multirow{7}{*}{$\frac{0}{\frac{0}{0}}$} & \multirow{2}{*}{$\begin{array}{l}\text { Fractional } \\
\text { Model-1 }\end{array}$} & MAPE & 0.252 & 2.1074 & 0.827 & 3.0496 & 1.6255 & 0.9459 \\
\hline & & & $\alpha$ value & 0.706 & 1 & 0.001 & 0.493 & 0.001 & 1 \\
\hline & & \multirow{2}{*}{$\begin{array}{l}\text { Fractional } \\
\text { Model-2 }\end{array}$} & MAPE & 0.2517 & 2.1074 & 0.827 & 3.0498 & 1.6258 & 0.9459 \\
\hline & & & $\alpha$ value & 0.855 & 1 & 0.501 & 0.747 & 0.501 & 1 \\
\hline & & \multirow{2}{*}{$\begin{array}{l}\text { Fractional } \\
\text { Model-3 }\end{array}$} & MAPE & 0.2503 & 1.5076 & 0.6611 & 2.1942 & 1.1771 & 0.6468 \\
\hline & & & $\alpha$ value & 0.947 & 0.469 & 0.386 & 0.384 & 0.584 & 0.545 \\
\hline & & Polynomial & MAPE & 0.2936 & 2.1074 & 0.8486 & 3.2434 & 1.7139 & 0.946 \\
\hline & \multirow{7}{*}{ 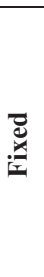 } & \multirow{2}{*}{$\begin{array}{l}\text { Fractional } \\
\text { Model-1 }\end{array}$} & MAPE & 0.1807 & 0.1425 & 0.2821 & 0.5068 & 0.2197 & 0.1124 \\
\hline & & & $\alpha$ value & 0.783 & 0.001 & 0.001 & 0.304 & 0.394 & 0.001 \\
\hline & & \multirow{2}{*}{$\begin{array}{l}\text { Fractional } \\
\text { Model-2 }\end{array}$} & MAPE & 0.1807 & 0.1425 & 0.2821 & 0.5068 & 0.2197 & 0.1125 \\
\hline & & & $\alpha$ value & 0.893 & 0.501 & 0.501 & 0.652 & 0.698 & 0.501 \\
\hline & & \multirow{2}{*}{$\begin{array}{l}\text { Fractional } \\
\text { Model-3 }\end{array}$} & MAPE & 0.1617 & 0.1393 & 0.1712 & 0.3978 & 0.2099 & 0.0941 \\
\hline & & & $\alpha$ value & 0.265 & 0.779 & 0.387 & 0.405 & 0.392 & 0.445 \\
\hline & & Polynomial & MAPE & 0.1809 & 0.1603 & 0.3249 & 0.5085 & 0.2289 & 0.1142 \\
\hline
\end{tabular}


When $N=10$, modeling of mobile broadband subscription yields $1.4679 \%, 1.46793 \%, 1.0728 \%$, and 1.5254\% average MAPE for Fractional Model-1, Fractional Model-2, Fractional Model-3, and Polynomial Method, respectively. Modeling fixed broadband subscriptions yields $0.2407 \%, 0.2407 \%$, 0.1956\% and $0.2529 \%$ for Fractional Model-1, Fractional Model-2, Fractional Model-3 and Polynomial Method. For both cases, Fractional Model-3 outperforms other methods. The best-modeled country is France while Spain produces the largest MAPE values. All optimized fractional-order values are different than 1 for modeling the fixed broadband subscription. As seen from the results, increasing exponent value $N$ decreased the error rates. All fractional models produced smaller error values compared to the Polynomial Method. Table 2 shows the superiority of the proposed Fractional approach over the conventional Polynomial approach.
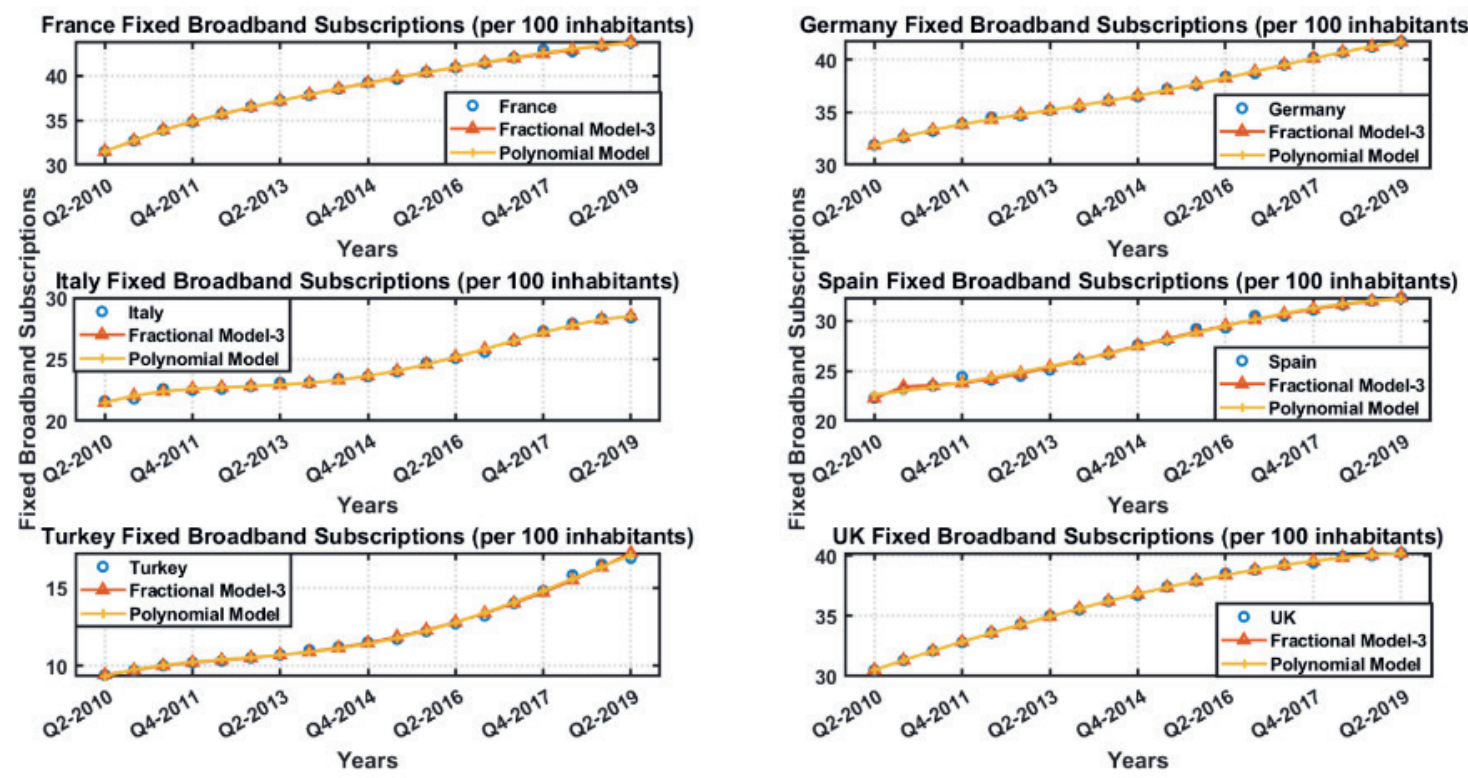

Figure 2. Fixed broadband subscriptions for $N=5$
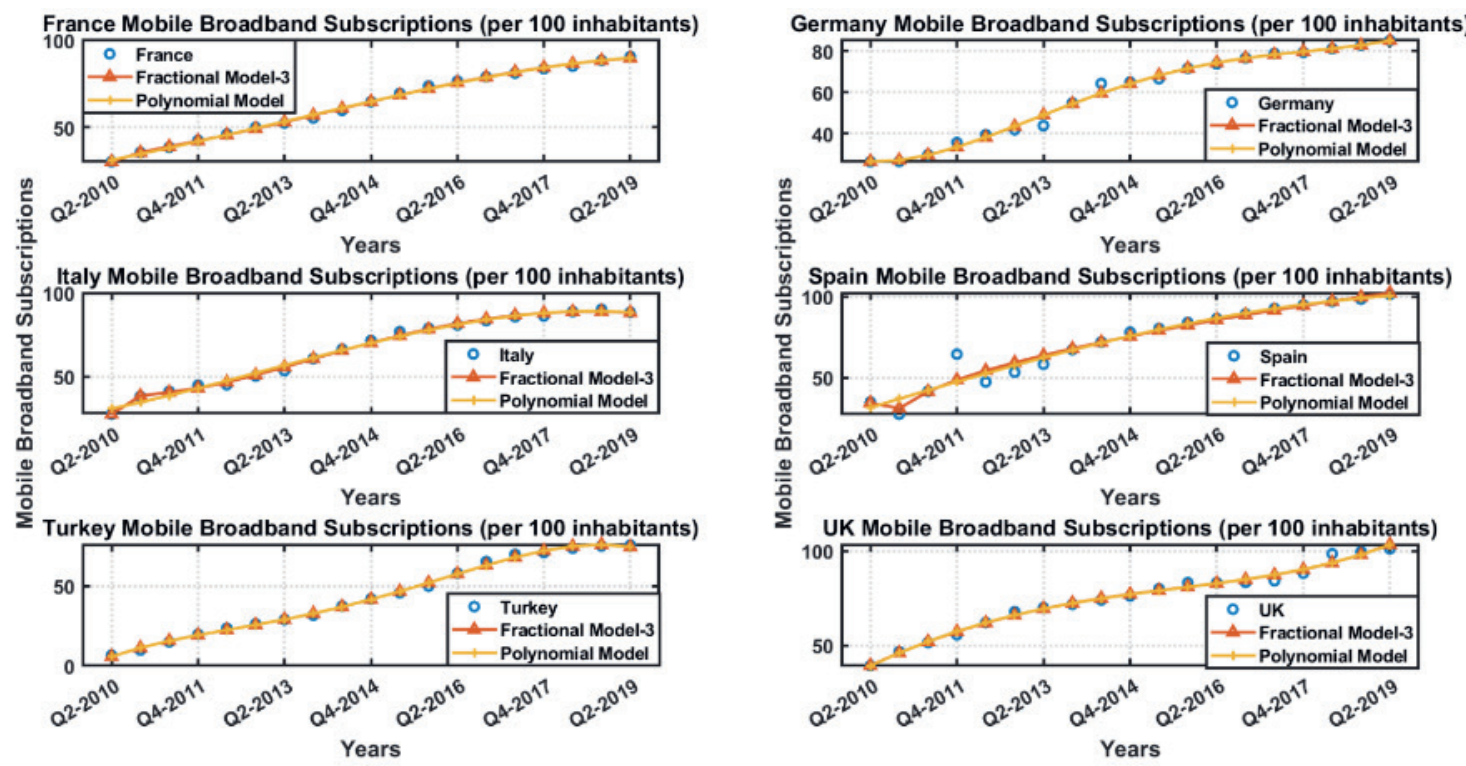

Figure 3. Mobile broadband subscriptions for $N=5$

Figure 2-5, represents Mobile and Fixed Broadband Subscriptions for two $N$ values (5 and 10) from 2010 to 2019. When left-hand side and right-hand side figures are compared, it is seen that increasing the exponent value helps to achieve better modeling results. Setting exponent to 10 helps to fit small fluctuations in the dataset. As seen from the figures, from 2010 to 2019, fixed broadband 
subscriptions generally increased in all countries. 30 subscriptions in France rose to about 45, 20 subscriptions in Italy rose to about 30, 10 subscriptions in Turkey increased approximately 17, 30 subscriptions in Germany rose about 42, Spain 22, about subscriptions It increased to 32 and finally 30 subscriptions in the U.K increased to about 40 (per 100 inhabitants). The lowest fixed broadband subscriptions in Turkey in 2010 and has seen the highest fixed broadband subscriptions in France in 2019. Similar to fixed broadband subscriptions, mobile broadband subscriptions also increased from 2010 to 2019. 30 subscriptions in France rose to about 90, 25 subscriptions in Italy rose to about 80,10 subscriptions in Turkey increased to about 70, about 30 subscriptions in Germany rose 90, Spain, about 40 subscriptions It has increased to 100 and finally the subscription from 40 in the U.K has increased to about 100 (per 100 inhabitants). The lowest mobile broadband subscriptions in Turkey in 2010 and the highest mobile broadband subscriptions were seen in 2019 in the U.K.
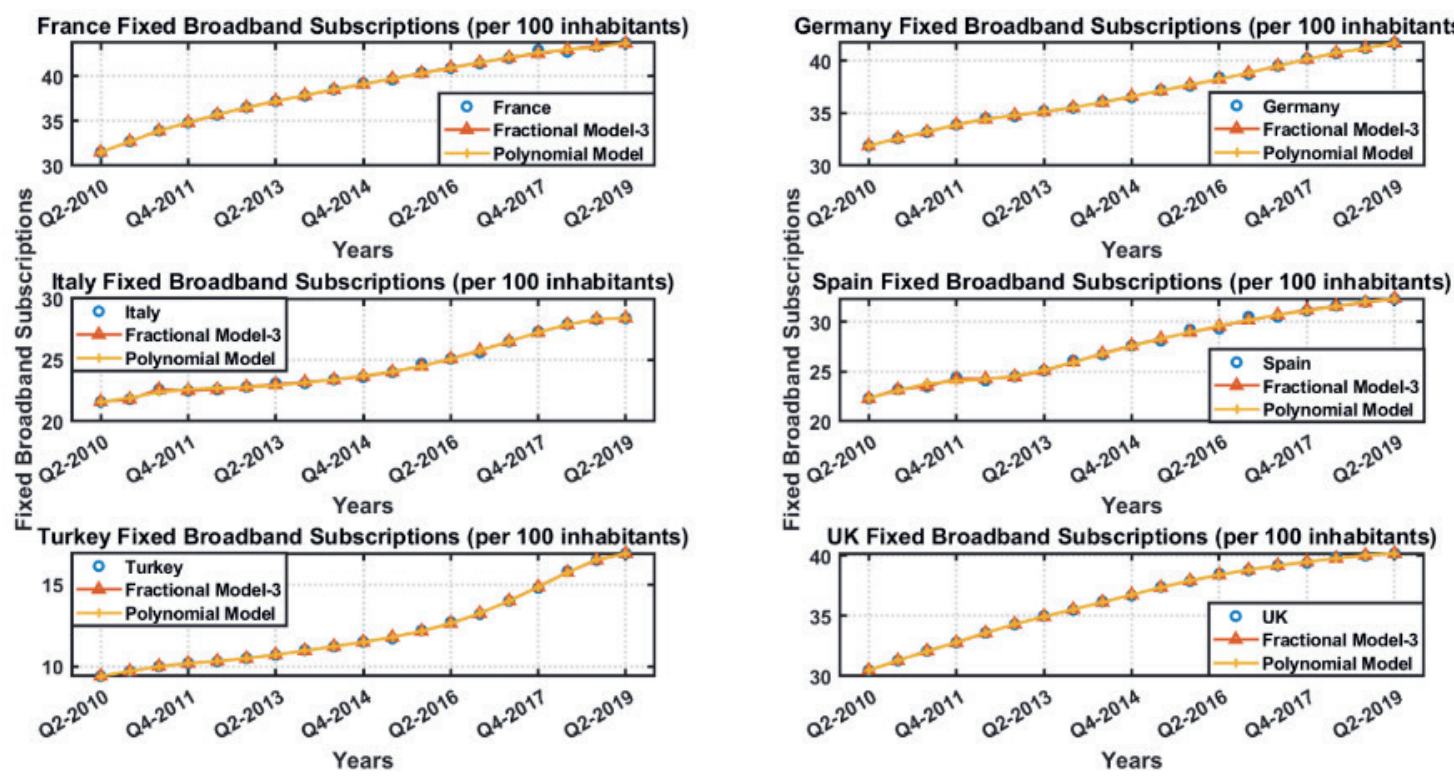

Figure 4. Fixed broadband subscriptions for $N=10$
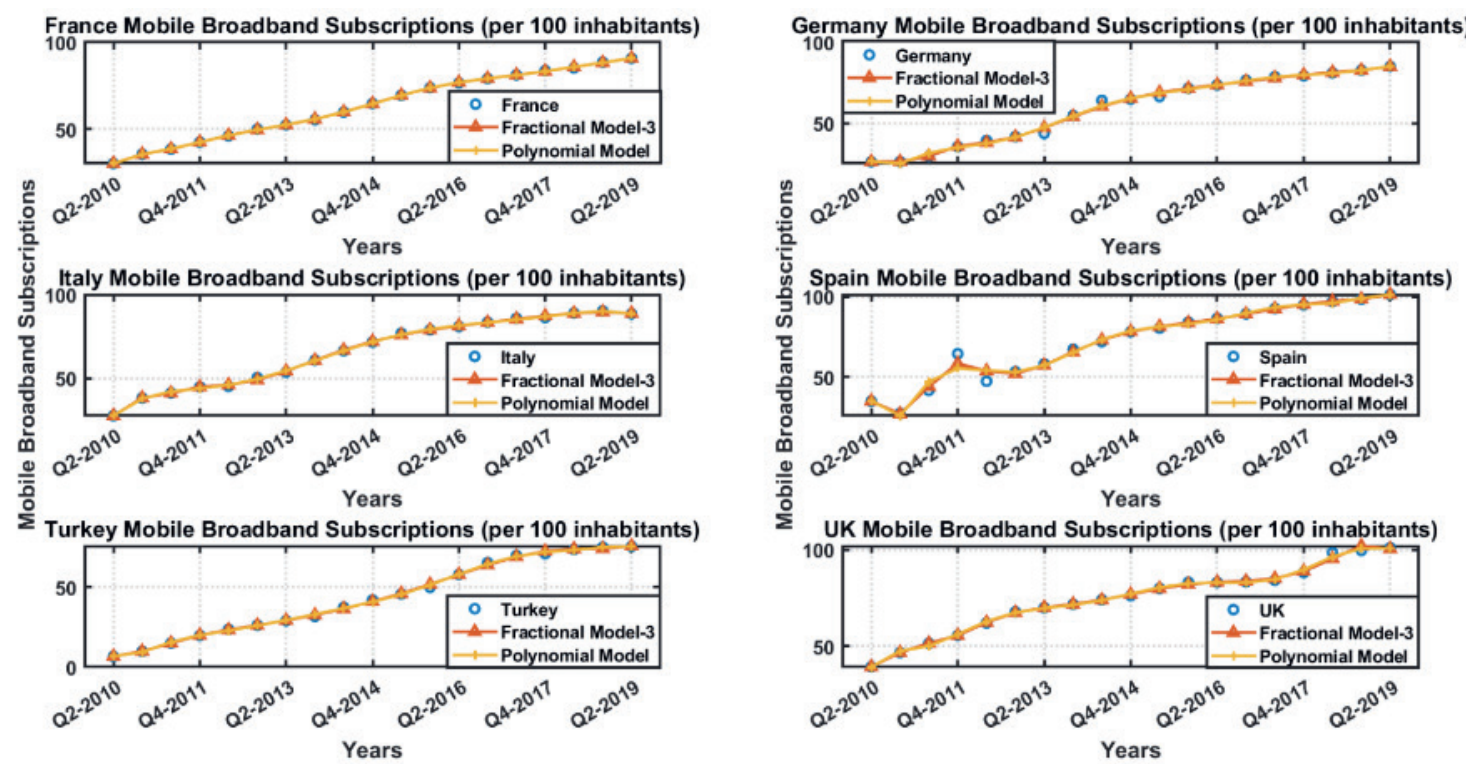

Figure 5. Mobile broadband subscriptions for $N=10$

To summarize, we modeled fixed and mobile broadband subscriptions using four mathematical approaches: Fractional Model-1, Fractional Model-2, Fractional-3, and conventional Polynomial method. The model called Fractional Model-3 is a method we developed using fractional calculus. In this study, 
modeling was done by using broadband subscriber data of countries (France, Italy, Turkey, Germany, Spain, and the U.K). MAPE values were compared to measure the success of the models. When we examine the results, it is seen that the model we proposed modeled better than the polynomial model, which is the classical modeling method.

\section{Conclusions}

In this study, we proposed an original mathematical approach named Fractional Model-3. We modeled mobile broadband and fixed broadband subscriptions of France, Italy, Turkey, Germany, Spain, and the U.K with four different mathematical models. Experiments are carried out with two different exponent values, 5 and 10 .

When the exponent is equal to 5 the average MAPE values, for Fractional Model-1, Fractional Model-2, Fractional Model-3, and polynomial methods, modeling the mobile broadband subscription of the selected countries are $2.730 \%, 2.739 \%, 1.0728 \%$, and $1.5254 \%$, respectively, whilst the average MAPE values of modeling the fixed broadband subscriptions of the same selected countries are yields $0.3888 \%, 0.3889 \%, 0.36555 \%$, and $0.4084 \%$, respectively.

When $\mathrm{N}=10$, average MAPE values of mobile broadband subscriptions have resulted in $1.4679 \%$, $1.46793 \%, 1.0728 \%$ and $1.5254 \%$ for the fractional model-1, Fractional Model-2, Fractional Model-3 and conventional approaches and similarly, for fixed broadband subscriptions MAPE values are found as $0.2407 \%, 0.2407 \%, 0.1956 \%$ and $0.2529 \%$, respectively.

Increasing the number of exponents $(N)$ in the calculation yields better results for both methods and using the fractional approach for modeling the discrete data leads to having better outcomes. The results show that Fractional Model-3 yields the least error rates on modeling both Fixed broadband and Mobile broadband subscription and is preferable over two other fractional approaches and polynomial model.

\section{Acknowledgements}

This work is supported in part by Istanbul Technical University (ITU) Vodafone Future Lab under Project No. ITUVF20180901P11.

\section{References}

1. Ahn, H. and Lee, M. (1999) An econometric analysis of the demand for access to mobile telephone networks. Information Economics and Policy, 11, 297-305.

2. Albon, R. (2006) Fixed-to-mobile substitution, complementarity and convergence. Agenda: A Journal of Policy Analysis and Reform, Jan 1, 309-322.

3. Briglauer, W., Schwarz, A., Zulehner, C. (2011) Is fixed-mobile substitution strong enough to deregulate fixed voice telephony? Evidence from the Austrian markets. Journal of Regulatory Economics, 39(1), 50-67.

4. Srinuan, P., Srinuan, C. and Bohlin, E. The Mobile Broadband and Fixed Broadband Battle in Swedish market. In: 21st European Regional ITS Conference, Copenhagen, Denmark, 13-15 September 2010, No.33.

5. Unwired Insight (2007) Analysys Research Fixed-Mobile Substitution is Accelerating. Online Available: https://www.unwiredinsight.com/2007/fixed-mobile-substitution (accessed on 8 May 2020).

6. Pita Barros, P. L., Cadima, N., \& Centre for Economic Policy Research, London (United Kingdom); (2000) The impact of mobile phone diffusion on the fixed-link network. CEPR Discussion Paper Series (Vol. 2598).

7. Narayana, M.R. (2008) Substitutability between mobile and fixed telephones: Evidence and implications for India. Review of Urban \& Regional Development Studies: Journal of the Applied Regional Science Conference, 22(1), 1-21, Melbourne, Australia: Blackwell Publishing Asia.

8. Ward, M.R., Woroch, G.A. (2004) Usage Substitution Between Fixed and Mobile Telephony in the U.S., CRTP WorkingPaper.

9. Sugolov, P. (2005) Are Mobile Phones and Fixed Lines Substitutes or Complements? Evidence from Transition Economies. Doctoral dissertation, Department of Economics-Simon Fraser University.

10. Rodini, M., Ward, M.R., Woroch, G.A. (2003) Going Mobile: Substitutability Between Fixed and Mobile Access. Telecommunications Policy, 27, 457-476.

11. Horvath, R., Maldoom, D. Fixed-Mobile Substitution: A Simultaneous Equation Model with Qualitative and Limited Dependent Variables. In: Regional ITS conference in Madrid, August, 2002 Issue 02(02). 
12. Garbacz, C. and Thompson Jr,H.G. (2007) Demand for telecommunication services in developing countries. Telecommunications Policy, 31, 276-289.

13. Garbacz, C. and Thompson Jr, H.G. (2005) Universal telecommunication service: A world perspective. Information Economics and Policy, 17, 495-512.

14. Royston, P., \& Altman, D. G. (1994) Regression using fractional polynomials of continuous covariates: parsimonious parametric modelling. Applied statistics, 43(3), 429-467.

15. Önal, N. Ö., Karaçuha, K., Erdinç, G. H., Karaçuha, B. B., \& Karaçuha, E. (2019) A mathematical model approach regarding the children's height development with fractional calculus. International Journal of Biomedical and Biological Engineering, 13(5), 252-260.

16. Podlubny I. (1998) Fractional differential equations. 1 st ed., Elsevier, San Diego.

17. URL1 (2021) OECD Broadband Portal. https://data.oecd.org/broadband/mobile-broadbandsubscriptions.htm, last accessed: 2021/09/29.

18. Gautschi W. (1997) Numerical Analysis. Springer Science \& Business Media, Berlin, Germany. 